\title{
EFEITOS MATERIAIS DA SEPARAÇÃO JUDICIAL/ DIVÓRCIO. \\ CONJUGALIDADE: DESCASAMENTO, RECASAMENTO E O FIM DO AMOR ${ }^{1}$
}

Jussara Suzi Assis Borges Nasser Ferreira*

SUMARIO: 1. Efetos materiais no pensamento dassico. 2. Descasamento e Obrigacăo Alimentar. 2.1 Naturea jurdica da Obrigacho Almentar. 3. Descasmonto e Culpa. 3.10 Passado. 3.2 O Prescnte, 4. Confíluão. 5. Bibliografia.

SUMMARY: 1. materid effects in the classic though. 2. "Un-marrage" and Almentary Obligation. 2.1 juridial nature of the Alimentay Oblgation. 3. "Un-mamiage" and it Accuses. 3.1 the Past. 3.2 the Present. 4. Condusion. 5. Bibliogrophy.

UBERSICHT: 1. Materielle Wirkungen im kassischen Rechtsderiken. 2. Bendigung der Ehe whd Unterhalispllicht. 21 Rechsnattir der Untemalspflicht. 3. Beendigung der Ehe und Verschiden 3.1 Vergangenheit. 3.2. Gegenwant 4. Schlusfolgerang. 5. Biblographic.

RESUMO: O artigo trata da natureza juridica da obrigacăo alimentar a a culpa no descasamento.

ABSTRACT: The artide discuss the juridical nature of alimentary obligation and the fault in the "un-marriage".

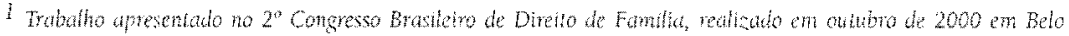
Horiggiang.

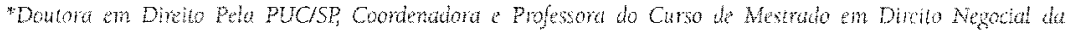
Enwewidade Estahol de tonding
} 
ZUSAMMENFASSUNG: Der Aufatz behandelt die Rechtsnatur der Unterhaltsplicht und las Verschulden bei Beendigung der Ehe.

PALAVRAS-CHAVE: Separaçăo judicial. Divórcio. Descasamento. Recasamento. Obrigaçăo alimentar.

KEY-WORDS: Judicial separation-divorce. Un-marriage-remarriage. Alimentary obligation.

SCHLUSSELWÖTER: Gerichtiche Trennung. Scheidung Beendigung der Ehe. Wiederverheiratung. Unterhaltspllicht.

\section{Efeitos materiais no pensamento clássico}

Odescasamento tradicionalmente produzia, como efeito material, igualmente clássico, a partiha do património.

Yussef Cahali nas primeiras ediçoes da notâvel obra Divórcio e Separaça ainda abordava, em capítulo apartado, täo somente a partilla do patrimònio considerada como efeito material.

Assim era, sendo que esta direção de pensamento dominava, em parte expressiva, a doumina pátria. Somente após alguns movimentos evolutivos do direito de familla é que a pensão alimenticia passou, delinitivamente, para o rol das patrimonialidades.

Vigia a regra do art. 320 do C. C. (revogado) que impunha, como condiço fundamental; "no desquite judicial sendo a mulher inocente e pobre, prestar-lhe-á o marido a pensão alimenticia, que o juiz fixar".

A Lei do Divóncio, em seu art. 54, revogou 320 do C. C., dispondo no ant. 19 que o conjuge responsável pela separaço judicial prestará ao outro, se dela necessilor, a pensao que o juz fixar.

Assim o artigo 19 da Lei reproduz, em substancia, a disposição do 320 C.C., apenas substituindo a adjetivacão emprestada à pessoa do conjuge culpado, agora erigido em cônjuge responsável. 
Na crítica cahaliana em nome de um escrupulo pueril, mudaram-se as palavras mas conservou-se o primitivo conceito. Vale dizer: o secular conceito de culpa estava e continuava incrustado nas texturas estruturais da concessão ou não da pensão alimenticia. A proposição - mulher honesta permanecia, apenas que, de lorma subliminar.

Neste final de milênio a estreita visão económica do patrimônio atende à ruptura imposta pelos padrões morais, sociais e legais, para alargar a interpretação clássica. Desponta o patrimônio moral do indivíduo. A teoria da moralidade impregnou o frio campo das riquezas amoedadas, que então e necessariamente, reconhece a legitimidade do patrimônio maior do individuo, expresso, no mais das vezes, de há muito, pelos direitos fundamentais.

Segundo a observação das mudanças verificadas, necessário se torna reconceituar patrimônio, no passado tido e reconhecido de forma univoca, en sua dimensão financeira.

Defende Dr. José Maria Trepat Cases, em Tese de Doutoramento, recentemente, sustentada junto à USP, e, aprovada com distinça, que elementos passivos, sendo que estes primeiros estariam divididos em: direitos disponíveis e direitos indisponiveis (pág. 90). Ao finalizar a propositura da teoria irrestritiva ou imaterial, verifica-se que seus elementos constitutivos alteram atual conceito de patrimonio. Propoe-se, entäo, uma nova conceituaço que assimile as alteraçoes introduzidas pelo novo pensamento, onde: Patrimonno e conjunto de relacoes juridicas de uma pessoa ou ente, destinadas a um fim determinado, dotadas ou näo de valoraçăo economica (sem grilo no original - pág. 104).

O Direito de Família, deverá ancorar, distintamente, novas tutelas protetivas de patrimonio que tal, através da adequada dimensāo juridica.

\section{Descasamento e obrigaçâo alimentar}

Por estar sendo focado, com exclusividade, a questäo da materialidade pensionada, não será abordada, nesta fase, a partilha do patrimônio, tema reservado ao Dr. Euclides Benedito de Olveira, neste Painel. 


\subsection{Natureza Juridica da Obrigaçäo Alimentar}

Reafirmando a melhor doutrina, fundamental se torna pontuar a natureza juridica da obrigação alimentar, que pode derivar da lei, cle ato de vontade 'senso lato', de sentença condenatória por reparação de dano causado por ato ilicito e em decorrência de uniäo estável.

Na obrigação alimentar decorrente da lei, os alimentos săo aqueles bastantes para atender as necessidades com a alimentação, vestuário, educação. Devendo atender ainda, como indica o melhor direito alienígena, a saúde.

Esta obrigação não expressa de "per si", qualquer natureza indenizatónia, antes reafirma o purismo da obrigação alimentar, considerada etimologicamente como derivada de "alimentum", significando nutrir.

Numa das definiçoes possiveis, alimentos são prestaçoes para a satisfação das necessidades de quem não pode prové-las por si

Contudo, tanto o direito comparado, como o direito pátrio sinalizam para uma possivel natureza mista da obrigaçāo alimentar, com o que nāo há porque concordar, a nāo ser por vício ou tendência de ecletismo.

O ponto curial de posicionamento que tal, justifica, na medida possivel residir na obrigação alimentar, um caráter alimentar e um fundamento indenizatório.

Marty e Raymond, citados por Yussef Said Cahali explicam que quanto ao seu fundamento, a pensão é propriamente uma indenização levada à responsabilidade do conjuge culpado, para a reparação do prejuizo causado por sua culpa; mas esse dano tem um caráter peculiar, que consiste na privação do direito de assistência e socorro de que poderia prevalecer-se o cônjuge inocente se o divórcio năo tivesse dissolvido o casamento: o melhor meio para a reparacão desse prejuizo é o de conferir ao requerente do direito alimentar tanto quanto possivel correspondente aquilo que ele poderia auferir se o casamento tivesse perdurado, é por isso que, se o fundamento da pensăo é indenizatório, seu caráter é alimentar como aquele da obrigação de socorro. 
Com o maior respeito, deve ser anotado que a argumentaçăo é louvável, mas o fundamento apresenta-se desfocado, conduzindo, igualmente, a uma conclusão também desfocada.

A natureza, o caráter e o fundamento da pensão devida ao conjuge é, por preceito legal, direito alimentar. Assim o fundamento está presente na necessidade de um dos cônjuges, o caráter daí decorrente só pode ser o alimentar.

O exercício exegético sob estudo é considerado como intelectualmente delicado. Por analogia aponta resultado idêntico àquele decorrente da reparação por ato ilícito em que vindo um dos cônjuges a falecer, em regra o varão, o conjuge viúvo e filhos, por exemplo receberão pensão alimentícia, equivaiente ao tempo de vida estimado e conseqüente obtenção de benefício laboral que o falecido percebia, se vivo fosse. É preciso cautela.

Defender que o melhor meio para a reparação do prejuízo causado pela separaçăo está em conferir ao requerente o direito alimentar, é inadequado. Sobrepor ao direito alimentar moldura indenizatoria é equívoco, ou pior, ideologia falsa a desfavor do cônjuge inocente, que em verdade não recebe um plus indenizatório, como apregoado. Recebe sim e tăo somente, alimentos necessários ao sustento. Os tribunais reiteram e até especificam o destino do quantum alimentício. Não se conhece ou são raras, decisões determinando indenizaçoes em paralelo com o quantum apurado a título de direito alimentar. Desta forma, por crença, convicção ou o que é mais grave, por equivoco, imperdoavel, da melhor hermeneutica deste século que principia por terminar, se definiu a mais nobre ou mais pobre ficção jurídica acerca do fundamento indenizatório do direito alimentar. Finalmente exsurge, com nitidez, o caráter tipicamente alimentário da pensäo, arredando, em definitivo, o caráter indenizatório que os alimentos não tinham e nem poderiam ter, como afirmado, pelo S.T.F, no passado e referido na decisăo, trazida à colação no próximo item.

Robustece a afirmação, reconheço, contundente, decorrente da nova leitura do direito alimentar quando vezes incontáveis apresenta-se, e, nesta hora, de forma correta, escudado no pressuposto, requisito e fundamento da 
necessidade do alimentando. Invoca um direito quem dele é sujeito e necessita de tutela. Indeniza-se aquele que solre um prejuizo um dano. A pensão alimentícia prestada ao cônjuge, até onde se conhece não chegou a cobrir dois santos. O quantum, o valor da pensão sempre foi modelo de pano curto como diz o dito popular, em verdade sem nada indenizar.

\section{Descasamento e culpa}

A histónia só vai em frente. A teoria deve conscientizar as decisóes tomadas pela nova época. Ela deve propulsar medidas necessarias, para remediar, na medida do possivel, os danos com efeito alienante, causados à natureza humana. Na medida do possivel, pois a incerteza acerca do que é correto inclui que nenhum espirito universal propele a historia no rumo de sua salvação. O momento correto para rupturas há muito vencidas pode ser perdido, a história pode inveredar por descaminhos.

Quando a teoria e recepcionada como aquela que deve conscientizar decisões, medidas necessárias, indicar o momento para rupturas, resta destacado pelo relevo da investigação científica, aquilo que há de fundamental, relativamente às céleres mutações sócio-juridicos e culturais.

\subsection{O Passado}

A concessão da pensão alimentícia sempre esteve atrelada à caracterização da culpa que estando presente arreda qualquer possibilidade de prestação. Os alimentos eram concebidos como indenização e ainda seguindo uma postura compensatória. A culpa reciproca expressou a inviolabilidade da subsistência da pensão em favor dos cônjuges. O 5.TJ. consagrou este viés interpretativo. A reconhecida autotidade do ministro Otávio Gallotti, a seu tempo, autorizava a expressão do voto seguinte: O dever de mútua assistencia decorre originalmente da sociedade conjugal em caso de separação judiciai nào consensual (art. $5^{\circ}$, capul, da Lei 6.515/77), só subsiste em favor do cônjuge necessitado, a quem não se possa irrogar a responsabilidade pela separaçāo. A declaraçäo de reciprocidade de culpas não caracteriza essa 
isenção de responsabilidade, denota a sua existência ex exlui, para ambos os conjuges, o divito de percepcăo de alimentos. Penso ser esta a melhor interpretaçāo do art. 19. Com efeito, os alimentos pagos por um cônjuge ao outro, ou são resultados de convensão, ou têm origem na culpa de um dos cônjuges, hipótese em que têm caráter indenizatório.

\subsection{O Presente}

O tempo era outro. A indisfarçàvel inserção cultural e histórica daquele corpo legislativo conferia e ainda confere o estreito liame entre o Código Civil e a estrutura social do pais, espelhado no desenho juridico dos três pilares fundamentais da ordenação privada: a familia, a apropriação e o trânsito jundico assentado nos contratos. Segundo Luiz Edson Fachin que lala, evidentemente, de nossa codificação civilista do inicio de século, mas pretende-se um deslocamento, para alcançar também a Lei do Divórcio e por igual, a Lei de Alimentos. Em sendo a familia um dos thès pilares fundamentais dos interesses privados, tornou-se indispensável a revisão de valores, conceitos e estruturas. O Direito da Família, gradativamente, desprende-se da rigidez do eixo dogmático que congelou certas concepções por décadas longas, obscurecidas pelo dogma da repressão sexual.

Yussel Cahali ensina: A causa juridica da pensão assim devida encontrasé no proprio casamento, que subsiste à separação, e não em qualquer outra; é na condiça de conjuge que o marido deve almentos a mulher durante a separacão de corpos... é em vinude dos arts. 212 e 214 do CC francês, e em cumprimento do dever de assistencia que se institui entre os conjuges aquela obrigacao... de que resulta que a pensāo pode perfeitamente ser concedida ao conjuge culpado, aquele contra o qual a separaça de corpos foi pronunciada, no pressuposto, bem entendido, de encontrar-se aquele em necessidade. Gradativamente, o criterio de aferiçăo da culpa, para concessão ou não de alimentos vai cedendo espaço para a não culpa, ou conforme a dicção legal - necessidade de alimentos. Afirma com percuciência Rodrigo da Cumha Pereira, ....não se deve falar em culpa na discussăo da concessăo de alimentos... O nobre e singular presidente do I e deste II Congresso Brasileiro de Direito de Familia, Rodrigo da Cunha Pereira, indicava, já em 1995, a imperiosa ordem: - afastar, de 
todo, a secular idéia de culpa dos pressupostos de admissão de alimentos. On line com Rodrigo Pereira, a dogmática crítica fachiniana, pontifica nessa travessia de milênio: "a solução legislativa é criticável. O termo responsável pode conduzir a absurdos, estando assentado na vetusta idéia de culpa, e que, gradativamente, no sistema brasileiro vem sendo abandonada. Fixado numa perspectiva axiológica, à luz dos princípios, deverá prestar alimentos aquele que puder fazê-lo se (e enquanto) o outro parente necessitar. Esta pode ser a razoável diç̧ão dos alimentos conjugais. Sem razäo alguma em nosso ver a afirmação segundo a qual o direito ao pensionamento pressupoe a inocência do conjuge pela ruptura da uniäo matrimonial". São chegados novos tempos. Assim, outro tanto, a família, impregnada de novos valores, exige que outras realidades e necessidades surjam como latores determinantes de mutações do status pretérito. A propósito, Gustavo Tepedino anota, com peculiar agudeza, as sensiveis modificações registradas, no que tange à concepção da família, a partir do texto constitucional vigente. Segundo o autor: A Constituiço da Republica de 1988, ao contrário, na esteira de longo processo histónico de transformação da estrutura familiar, em seus arts. 226 e 227 , altera radicalmente o quadro normativo. Estabelece a proteça da familia como meio para a realização da personalidade de seus membros, estremando a entidade familiar da entidade matrimonial, esta apenas uma espécie priviegiada daquela, admitindo-se, expressamente, a uniäo estável e as familias monoparentais, formadas por qualquer um dos pais e seus descendentes (sem grifo no original). o traço distintivo entre entidade familiar e entidade matrimonial impóe tratamento adequado considerando familia e casamento em seus respectivos planos nomativos. Na dicção tepediana a unidade da familia, a luz da Constituição, não mais se identifica com a unidade do casamento, não há como associar a aplicaçäo de sançoes atinentes a efeitos juridicos existenciais alimentos, guarda de fithos, sobrenome da muther - e mesmo patrimoniais - divisao dos bens - a culpa pela rupura do vincuto matrimonial. Os juristas referidos expressam a concepção pós-moderna em matéria alimentária. Com a superação da culpa, o pensionamento entre conjuges, na moldura jurídica, retorna à tela onde, em verdade sempre esteve, pintado pela codificação positiva e exposto na cor uniforme do dever de mútua assistencia, previsto no ant. 23], inciso III do Código Civil. 
A dissolução da sociedade conjugal por culpa do cônjuge desenhase no plano da infração aos deveres matrimoniais. Ao dever corresponde a prestação, dada a não prestação deve ser a sanção. Evidentemente, a sanção correspondente, in casu é a própria separação judicial. A relação jurídica nas texturas da não prestação tem seu ponto terminal, nos limites expressos, pela ordem jurídica. Inadequado ampliar o locus sancionatório como quis e ainda pretende o legislador divorcista e parte da doutrina, para alcançar a supressão dos alimentos. Leitura atenta das decisões judiciais permite constatar as diversas tendèncias jurisprudências, ora reafirmando, ora atenuando, a expressão do elemento culpa, em relação à concessão de alimentos. O S.T.J. por exemplo, em julgado de 1989 consignava: São indevidos alimentos na ocorrência de culpa reciproca, (art. 19 da Lei 6.515/77) Recurso conhecido e provido. (terceira turma, acordão 1989/00/0085 8) DJ de 20/11/1989 - pg. 17.294) . O colendo Tribunal reafirmava, vez mais, a questão da culpa recíproca acolhida, de maneira uniforme, pelos julgadores pátrios, como causa definitiva na exclusão, igualmente recíproca, sem pensionamento entre cônjuges. A culpa recíproca, espécie de culpa compartilhada parece expressar uma certa proporcionalidade da culpa representando fundamento seguro a indicar o desmerecimento recíproco de pensionamento entre cônjuges. A jurisprudência nacional ao aquilatar a ponderação da culpa em dupla direção procura evidenciar uma postura de suposto equilíbrio, como argumento representativo de uma justa decisão, extraído desta espécie de "culpa compartilhada". A atribuição da culpa unilateral, com a conseqüente exclusão de alimentos, encontra nos fundamentos da culpa recíproca estrutura farta, supostamente lógica, apta a justificar igual consideração de adequação das decisões dos tribunais. Assim não o é. Cabe a reafirmação de que as relações jurídicas em questão são distintas, como, igualmente, distintos os deveres jurídicos de cada uma. A infração aos deveres matrimoniais deve corresponder a conseqüência que daí decorre - em uma palavra - a separação judicial que se impõe. A prestação alimentícia tem por fundamento a necessidade do alimentando, escudada no mútuo dever de assistência entre cônjuges, não devendo ser alcançada pelo cego talante da lei. Romper com a prestação alimentícia fundada na exclusão por culpa de um dos cônjuges é ilógico, injusto e incorreto. Inexiste nexo 
causal real. Há apenas conexidade legal, imposta por disposição pretérita de lei, que descreve mal aquelas relaçoes, atribuindo aos valores morais relevo excessivo, quiçá ampliando o campo da culpa e adentrando, desmedidamente, nos domínios da moralidade de très décadas passadas para condenar a falta de alimentos aquele que necessita. Deve ser levado em conta as causas que motivam a necessidade de alimentos, muitas vezes geradas pelo agora e só agora, conjuge inocente. Demais disso, a relação jurídica em sede de alimentos é outra tanto que pleiteado em aça própria ou no máximo cumulada com a açăo de separaçäo. A mesma corte, anteriormente mencionada, em decisão prolatada anos depois, em 1995 sinaliza nova postura ao interpretar: se, antes mesmo da sentença na separaça judicial, as partes requerem o divócio direto, nos termos do art. 40 da lei 6.151/77, e irrelevante a disposiço daquela reconhecendo a culpa da mulher, para efeitos de alimentos. (Recurso Especial 1995/0028061-2 - DJ de 26/08/1996 - pg. 29.681). Em se tratando de divórcio direto não se exige prova da causa do pedido não sendo objeto de discussão a causa da separação de fato. O acordão relerido, bem por esses fundamentos arreda o reconhecimento da culpa da mulher para efeitos de alimentos. Contudo, näo deixa de sinalizar, ainda que escudado nas circunstancias do caso concreto, um certo abrandamento em relação à apuração da culpa. No mesmo ano o TJSP decidia: Separaçăo Judicial Contenciosa - culpa da mulher. Posse e guarda dos lithos. Alimentos. Nome do conjuge mulher considerada culpada. Näo havendo fundamento que justifique a posse e guarda dos filhos menores esta deve ser concedida a máe. O fato da mesma ter sido considerada culpada para a rupura do matrimônio por si só não justifica tal situação. Ao fixar os alimentos o juiz deve observar o principio da proporcionalidade consagrado em nossa legislação civiì, admitindo o binômio necessidade e possibilidade, aliado aos elementos circunstanciais que consolidam tal fixaçăo. Deve a sentença ao considerar o conjuge mulher culpada determinar o cumprimento da determinação legal em relação a modificação do nome de casada e a mudança do CPF. Provimento parcial do recurso. (ap. civ. 1996. 001.3165 . registrado em 27.11.96. Fls. 43.533/43559. (Sexta camara cível) - Julgado dessa lavra, além de consagrar a desconsideração da culpa referentemente à guarda dos filhos, (existem vários acordăos em igual 
sentido) inaugura igual desconsideração, agora em relação aos alimentos, mantendo, lamentavelmente, a modificação do nome de casada, com o que, evidentemente, não se pode concordar. Contudo o tema não será aprolundado, nesta oportunidade. A decisão consagra a admissão do critério - necessidade - recomendando ainda a verificação da possibilidade, enfatizando o relevo da invocação, pelo juiz, do principio da proporcionalidade ao fixar os alimentos. O grande equívoco está na subjetivação dos fundamentos e natureza juridica dos alimentos. Critérios de necessidade devem merecer absoluta objetivaça para de vez, desfazer a inbricaça vetusta que insiste, equivocadamente, em manter o subjetivismo própio da culpa, como requisito para a concessão ou não de alimentos. As estruturas legais e morais estão em permanente processo de renovação. Com a separaço da condiçào da família e do casamento pelo texto constitucional, resta possivel avançar um pouco mais, para escardir descasamento por culpa e direito alimentário.

Finalizando, e anotado o acerto do direito alienigena quando adota o pensionamento aprazado, determinando a pensäo com base no critério de necessidade aliado a capacitação de mão de obra do alimentando para o mercado de trabalho, como por exemplo, se conduz o direito alemào.

\section{Conclusão}

Em conclusão:

- A natureza juridica da pensão alimenticia não tem duplo caráter. Trata-se de direito alimentar e não de indenizaçăo; - Vanter a culpa como criterio de concessão da pensão alimenticia é incutir, erroneamente, a idéia de que o culpado esta sendo sancionado duas vezes;

- A culpa não deve integrar os requisitos de concessão da pensão alimentícia sendo substituida pelo critério de necessidade;

- Os alimentos tèm por fundamento a necessidade do alimentando e caráter exclusivo de direito alimentar decorrente do dever de mútua assistencia; 
- A pensăo alimentícia, sempre que possivel, deverá ser aprazada, objetivando possibilitar ao cônjuge que dela necessita conquistar condição (via laboral) de auto-sustento.

Em conclusão derradeira, pode ser afirmado, em sede de pensão alimentícia na separação ou divórcio, que o mito da culpa esta desmistificado. O fundamento bem localizado, o direito alimentar bem colocado.

Eram estas as consideracōes possiveis.

\section{BIBLIOGRAFIA}

CASES, Jose Maria Trepat. Tese de doutoramento USP/1099 - Teoria Inestritiva ou Imaterai do pammono, p. 90 e 104.

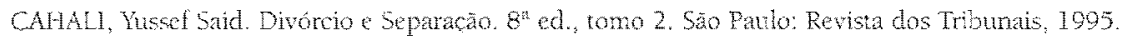

FACHN, Luiz Edson. Elementos Críticos do Direito de Familia: curso de direito civil. Rio de Jamelro: Renovar, 1999 .

MULLER, Fredrich, Igualdade c Nomas de Igualdade. 1978. Arquivo: Eguitice. Doc. Trad. Feter Natuann cm 1997.

PEREIRA, Rodrigo da Cunha. Concubinato e Uniăo Estavel. Belo Horizonte: Del Rey, 1995.

SUPERIOR TRIBUNAL DE JUSTICA. Jurisprudencias. Consultado na Internet em 16 de levereiro de 2000. http:/www.stj.gov.br

TEPEDINO, Gustavo - O papel da culpa na separacăo e no divórcio - As. 203. Repensando o Direito de Familia. Coordenador: Rodrigo da Cunha Pereira. Belo Horizonte: Del Rey, 1999.

TRIBUNAL DE JUSTICA DO ESTADO DO RIO DE JANEIRO. Jurisprucèncias. Consultado na Intemet em 16 de feverciro de 2000 . http:/www.t. govbr 